\title{
Congenital Reproductive System Abnormality
}

National Cancer Institute

\section{Source}

National Cancer Institute. Congenital Reproductive System Abnormality. NCI Thesaurus. Code C103185.

A disorder that affects the female or male reproductive system and is present at birth. Representative examples include ovarian agenesis, vaginal agenesis, and penile agenesis. 